\title{
Organization Cybernetics for Railway Supplier Selection
}

\author{
Mailasan Jayakrishnan ${ }^{1}$, Abdul Karim Mohamad ${ }^{2}$, Mokhtar Mohd Yusof ${ }^{3}$ \\ ${ }^{1,2}$ Centre for Advanced Computing Technology, Faculty of Information \& Communication Technology, Universiti \\ Teknikal Malaysia Melaka, Hang Tuah Jaya, 76100, Durian Tunggal, Melaka, Malaysia \\ ${ }^{3}$ Faculty of Computer and Information Technology, Al-Madinah International University, Pusat Perdagangan Salak 2, \\ No.18, Jalan 2/125e, Taman Desa Petaling, 57100 Kuala Lumpur, Malaysia.
}

\begin{tabular}{l} 
Article Info \\
\hline Article history: \\
Received December 24, 2020 \\
Revised April 21, 2021 \\
Accepted May 03, 2021 \\
Published June 15, 2021 \\
\hline Keywords: \\
Cybernetics \\
Data Analytics \\
Information System \\
Railway \\
Suppliers
\end{tabular}

\begin{abstract}
The comprehensive stimulation for this research arises from the necessity to continually understand and investigate the Information System (IS) discipline body of knowledge from organizational practice. Specifically, in this study, we focus on comparing a few available excellence frameworks, data analytics, and cybernetics approaches. Such knowledge and skill practice in the IS field is predominant for both IS research and teaching. On the other hand, to propose a relevant performance reporting model using data analytics and cybernetics that entail a body of knowledge and skill is crucial for the development and transformation of organizational excellence. Yet, it helps to design an online real-time organizational dashboard that produces knowledge for its application and decision-making within an organizational practice. IS discipline in an organization is comparatively young and its specification in academia as well as in practice is rapidly changing, we focus on the practical design, and IS structure for organizational excellence through employing information technologies.
\end{abstract}

\section{Corresponding Author:}

Mailasan Jayakrishnan,

Centre for Advanced Computing Technology,

Faculty of Information \& Communication Technology,

Universiti Teknikal Malaysia Melaka, Malaysia.

Email: m031620010@ student.utem.edu.my

\section{INTRODUCTION}

Good strategic performance diagnostics design, improve the way data is introduced as well as utilizing that data to settle on more intelligent choice strategically; it is a point-by-point application for performing the examination and revealing functional exercises on tending the issue of dissipated data in an industry by deciding the cycle of virtual information. The organizational excellence model is in sync with developing technology and the changing requirements of the upcoming trend in the organization itself and its relations with the technology revolution [1]. It can emphasize developing an organization for the change and aspiration the organization to adapt to such changes. One should welcome such changes before resisting them; after all, chronology has shown us that organizations that resist change soon die out in this rapid-changing technology world. This scenario occurs due to the complexity and diversity of IS disciplines, and the body of knowledge towards the social phenomena, business, and technology that are continually transforming and interacting with each other within an organization. As the IS discipline focus on generating knowledge that is applicable and relevant in practice, it inclines to develop in reaction to the embrace of these changing needs and phenomena in the organization's practice.

Besides that, it empowers the organization to accomplish its mission, improve results and become more competitive by establishing an integrated self-accessing progress or performance management system that helps the organization improve and innovate decision-making process using cybernetics elements on strategic performance diagnostic [2]. Cybernetics is the scientific approach of information that is moved and controlled in a specified system and automatically adapts to its environments [3]. Also described as adaptive, self-regulating, or self-organizing systems [4]. Cybernetics is the strand of systems science most suited to studying the management of organizational performance [5]. The organization's fundamental objective looking for frameworks of assorted types, such as strategic decision-making processes [6]. It focuses on the way organization managing the tools for 'targets,' 'reporting,' and 'planning,' considering an exceptionally rough arrangement of robotic ideas. Progress in management thinking depends on acquiring a better grasp of 
cybernetic concepts and refining comprehension of the science beyond management and figuring out how to utilize this information to plan better frameworks and cycles [7]. We are focusing on IS development, utilization, and management in organizational contexts, implicit phenomenon transpires in complex interactions.

\section{INFORMATION SYSTEM CLASSIFICATION}

A clear understanding of the taxonomy of a system plays a significant role in an organization. Taxonomy of an Information System (IS) in an organization can be categorized as (1) Deterministic (Mechanistic) System that emphasis on behavioral patterns for predicting accurately with $100 \%$ certainty for operation characteristics and functions with predefined procedures [8], (2) Probabilistic or stochastic systems outcome cannot be predicted with the precision of $100 \%$ accuracy or certainty that accomplished from explicit information because of these frameworks arbitrary impacts from the inner and outer climate [9]. Subsequently, it cannot emphasis because the system depends on probability, and (3) Cybernetic systems where the role of information in cybernetics control frameworks are in a condition of dynamic harmony [10]. Figure 1 presents four (4) unique manners by which these data streams in the context of organization cybernetics.

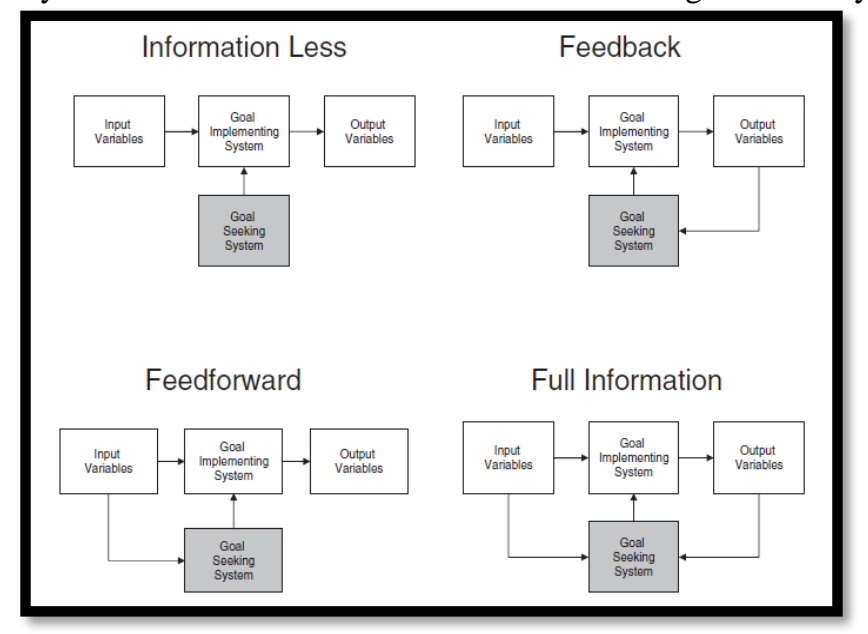

Figure 1. Cybernetics Decision Making Flow.

Based on Figure 1, cybernetics decision making flow focus on (1) information less emphasis on objective exists, no data about the presentation of the framework concerning the objective is made accessible to the framework, (2) feedback illustrates effective achievement of a goal must focus on the data condition of the goal-seeking system, (3) feedforward emphasis on hanging tight for blunder data, the objective looking for framework follows up on data about its likely future state to anticipate mistakes. The objective looking for the framework has a solid prescient model that provides effective decision-making control and (4) complete information employs both feedforward and feedback. Thus, the strategic decision-making process gives feedforward information that reveals the input to assist the industry more viably to accomplish its objective. Moreover, a clear understanding of cybernetics technology will be focused on the information that creates devices for assisting an organization's functions. This complexity and uncertainty control by cybernetics is present in Figure 2.

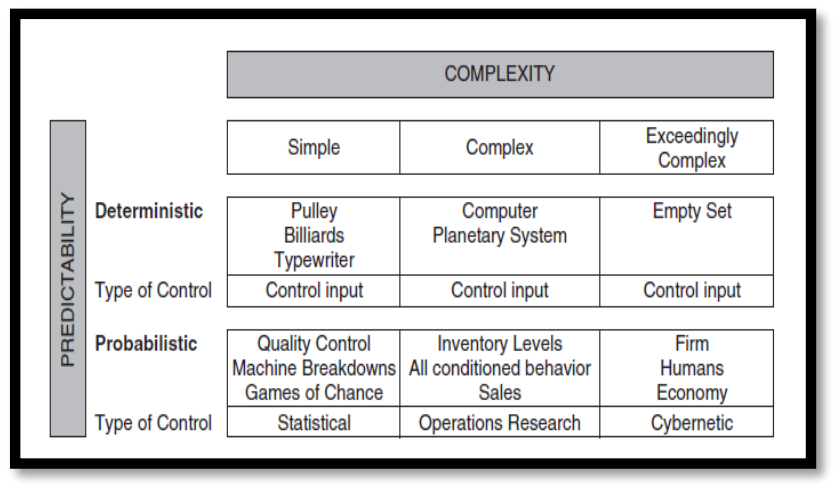

Figure 2. Cybernetics in Decision Making System. 
Based on Figure 2, cybernetics in the decision-making system is a generally new interdisciplinary science that worries information system functions and operations. Organizational Cybernetics (OC) is one of the framework approaches which, getting from Cybernetics, applies the principles from Cybernetics to organizations. OC was strategizing from both a theoretical and methodological perspective. OC describes the necessary and adequate conditions that an organization must fulfill in making a strategic decision process in an organization [11]. Yet, OC is the solid utilization of customary laws to the industry. OC has produced new organization open doors just as offering ascend to upgrades in the decision-making process, in the field of frameworks believing in creating new tools for analysis such as programming devices pointed toward encouraging the use of different frameworks systems. Moreover, the product devices empower the organization to appertain the strategic performance plan for various periods of the collective group in complex problems [12]. Furthermore, OC disciplines adopt for analyzing an issue from different views, by choosing various rules and levels to manage the intricacy of the climate. OC is a method of organizational behavior that emphasis on reasoning and learning to make use of information from a complex environment.

\section{Organization Cybernetics Characteristics}

Considering ideas from Organizational Cybernetics (OC), a dynamic approach needed to plan from the perspective of its characteristics. The characteristics layout empowers the organization to analyze or plan the industry in a structured decision-making process with the explanation of an industry's personality and underlying segments from the perspective of its strategic performance diagnostic. The fierce contemporary climate in which organizations should do their action necessitates that they utilize sufficient models for the errand [13]. Adding to their need, studies or research must be laid out a framework dependent on a foundational approach, explicitly on strategic performance diagnostic OC. The requirement for a fundamental methodology in the organization's decision-making process emphasis the way of foundational thinking and foundational executives [14].

Framework thinking gives a scholarly structure for numerous complex issues faced by organizations that require tools. In any case, these models that manage these issues have not generally advanced a multifaceted nature equivalent. Among the different hypothetical improvements accessible today for managing these sorts of issues, those gave by the foundational approach is especially appropriate. The systemic management approach attempts to comprehend the developing behavior of a framework produced by the organization's behavior and the interactions among them with the environment [15]. To develop a conceptual framework, we need to understand the OC methodology point of view from a positivistic convention and instrumental discernment ruled. Moreover, an interpretive tradition existed, and communicational judiciousness dominated. Figure 3 presents the vision of a blend of the two (2) streams, as evolved under the mark Integrative Systems Methodology.

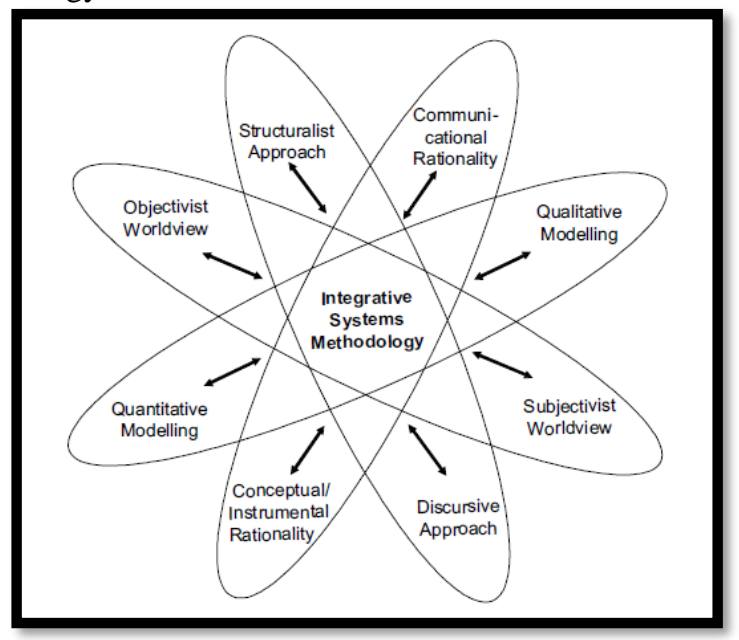

Figure 3. The Integrative Systems Methodology.

Based on Figure 3, the integrative systems methodology can guide researchers, developers, practitioners, and students to apply the cybernetic ideas for higher hierarchical execution, consequently beating the troubles in applying these ideas practically speaking. Yet, the framework provides parts inside a solitary system, which covers the overall structure, and the decision-making process within it. 


\section{The Architecture of Organizational Cybernetics Complex Control Systems}

The Organizational Cybernetics (OC) complex systems keep an excellent overall arrangement between stagnation (much negative criticism) and blast (an abundance of positive). Thus, the conceptual framework requires a more mind-boggling set of control game plans than the ones. Figure 4 shows the conceptual framework for OC control systems named 'versatile' since the objective is not forced from outside the framework yet gave by a subsequent control level - an objective producing a framework for strategic performance diagnostic.

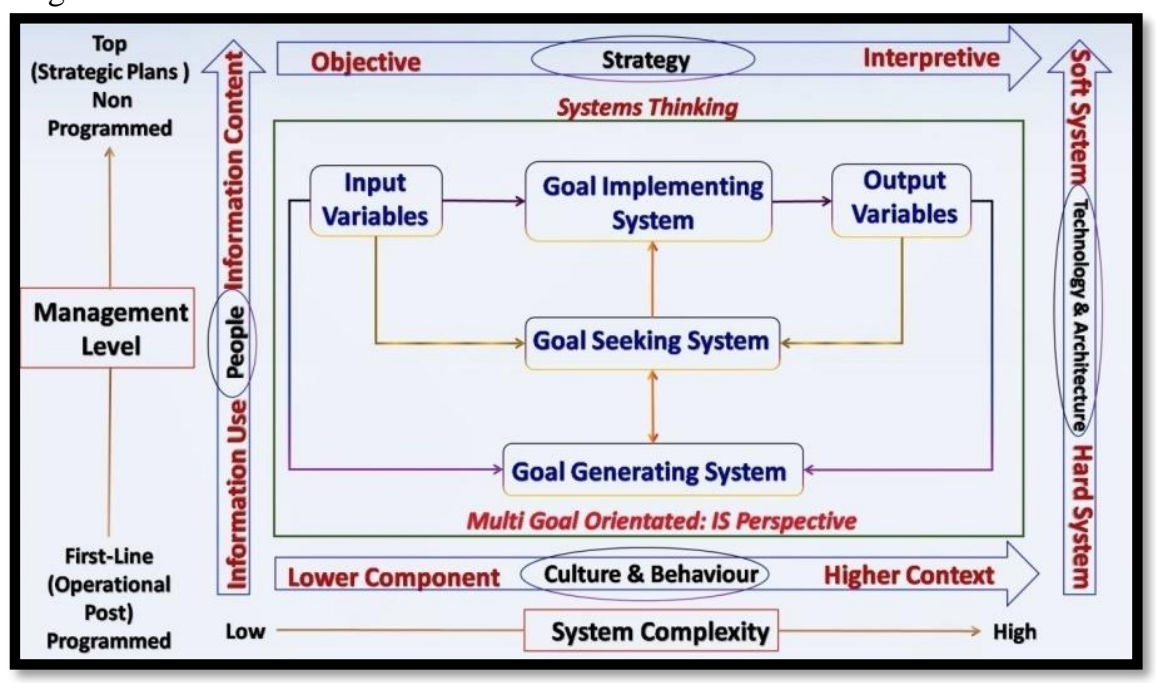

Figure 4. Conceptual Framework of Theoretical Adoption of Information System and Organizational Cybernetics.

Based on Figure 4, the conceptual framework of theoretical adoption of Information System (IS) and OC are to perform various tasks such as providing basic processing of transactions to interact with the organization through various communication technology systems. IS gotten limited in industry governmental issues since they impact admittance to critical source data [16]. Furthermore, IS conceivably changed in association structure, culture, legislative issues, and work [17]. Information systems in the organization management focused on the significant issues on the data needs and building up the data as an essential factor for the needs of top management [18].

The appropriation of IS in associations has been developing at a quick speed [19]. The utilization of innovation has advanced from the robotization of organized cycles to progressive frameworks that bring change into crucial organization methodology. In reality, the organizations will shape strategy and structure to fit new IS [20]. From a monetary viewpoint, IS be a factor of organization structure that is fill in for capital and work. As IS innovation automating the creation cycle, less capital and work are needed to deliver a predetermined field:

1. Economic impacts.

IS changes relative expenses of capital and data expenses by contract in size that lessens exchange costs.

2. Transaction cost theory.

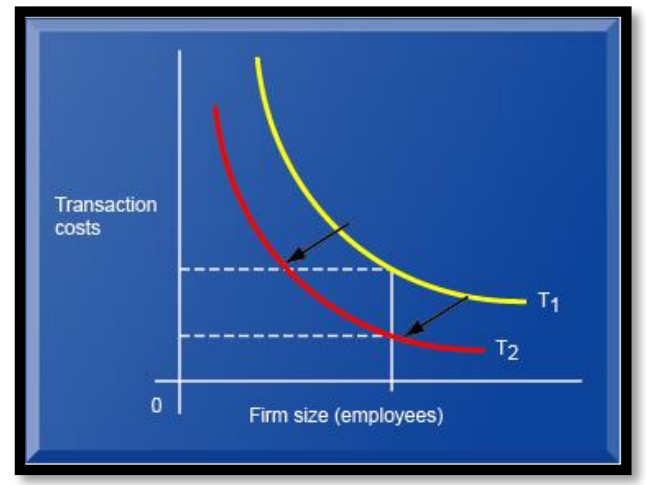

Figure 5. Transaction Costs. 
Consider the industry extends in size due to specific items or administrations inside conduct less expense through utilizing outer firms. The decrease in the expenses of the market, and lower cost of outside sources. IS would thus be able to help the organization to build income while contracting in size. Organizations contemporarily got extended in size to diminish exchange costs. IS potential bringing down the expenses for a given measurement by moving the exchange cost bend internal and opening the conceivable outcomes of income development even without expanding the size or even income development conveyed all the while by contracting size.

3. Agency theory.

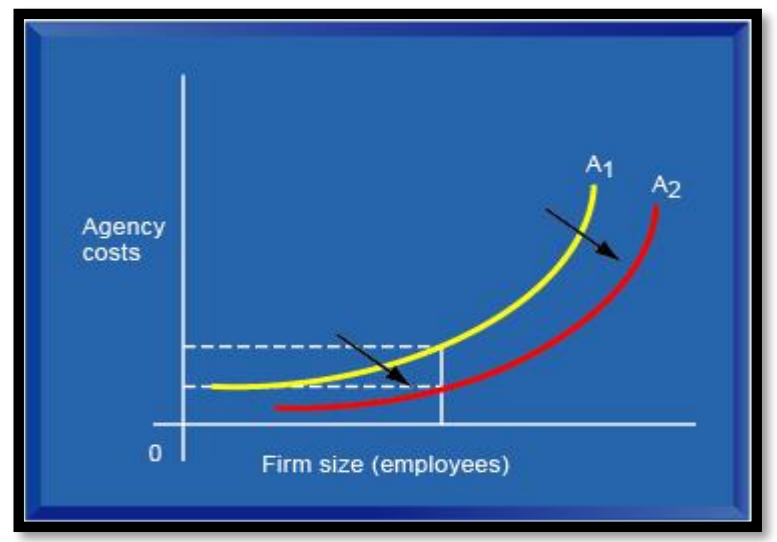

Figure 6. Agency Costs.

Observes the organization as an infinite connection of agreements among self-intrigued people, who should be painstakingly monitored and managed to make sure that they follow the industry's interests. IS can assist in diminishing organization costs, bring together a wide range of individuals, and exercises to result that every decision-making process can observe a bigger scale.

4. IS flattens organization.

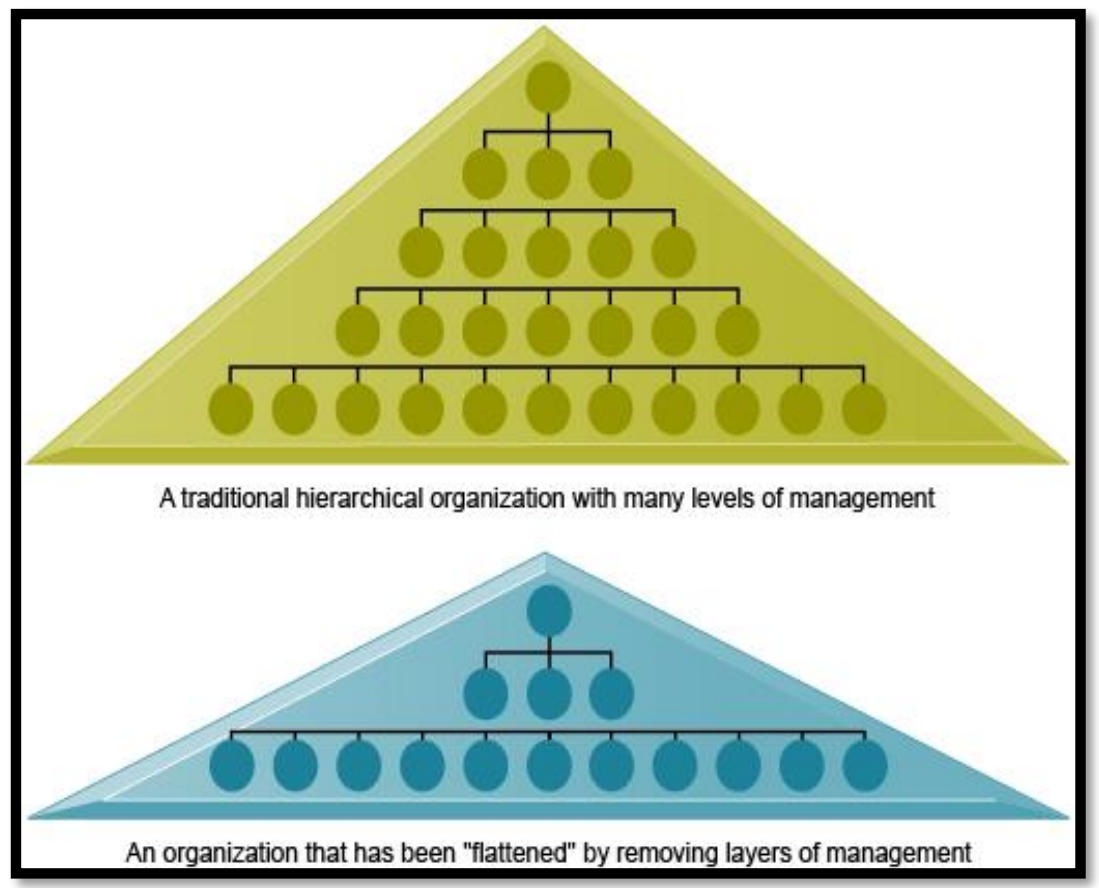

Figure 7. Information System Organization.

IS can diminish the number of levels in any industry by providing a legitimate measure of data to regulate and screen more significant quantities of the decision-making process and give a lower-level dynamic position. 
5. Post-industrial organization.

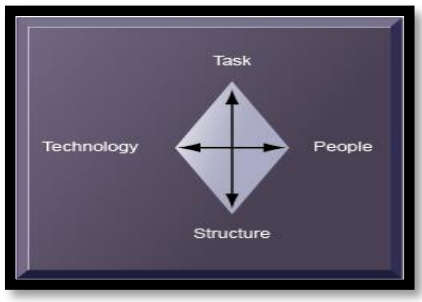

Figure 8. Post-Industrial Organization.

Backing the idea that IS should pack progressions by empowering experts to act naturally overseeing, by decentralizing dynamic, and empowering the arrangement of impromptu, brief 'teams' that address explicit assignments, technology, structure, and people simultaneously.

Therefore, this analytical framework is designed as the fundamental prototype system for the Railway Supplier Selection Performance and embedded with the OC diagnostics tool for data analytics. Yet, we have structured the policy and strategy implementation components as shown in Table 1.

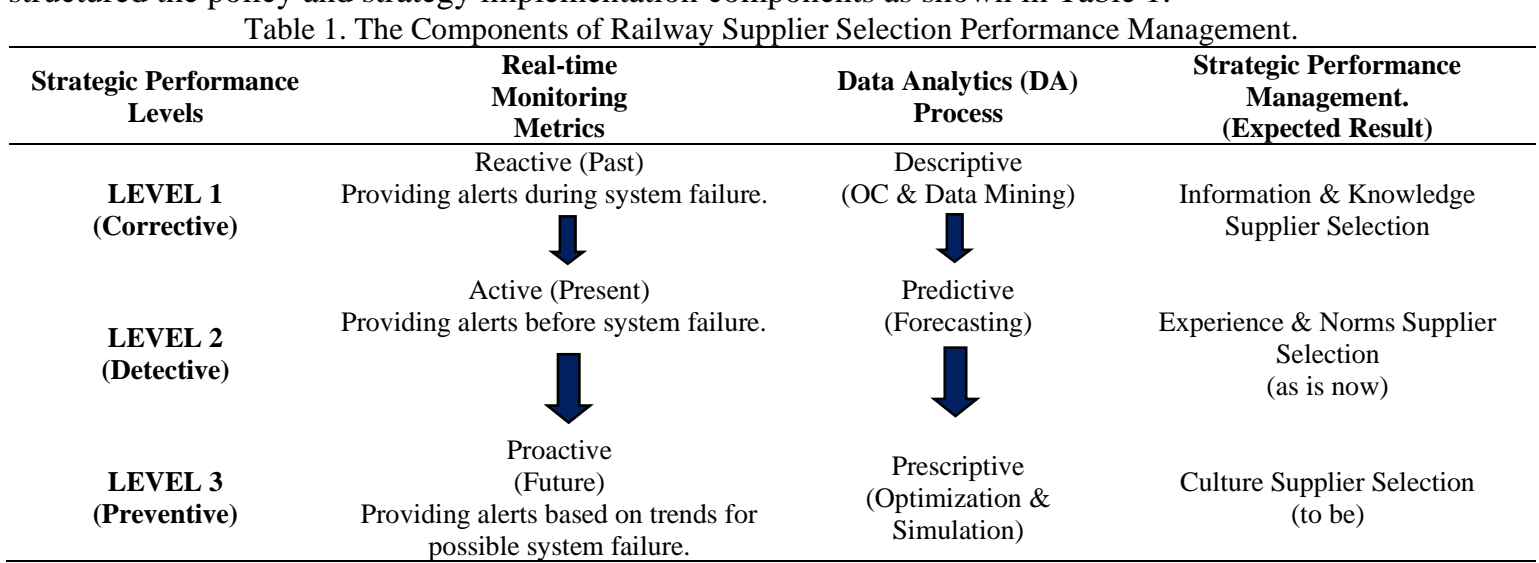

Based on Table 1, the components of Railway Supplier Selection Performance indicate a higher level of data analysis and provides a real-time alerting system. The outcomes produce level 1 descriptive analytics for supplier selection that focuses on the reactive process and simulating the events that already happened. The level 2 predictive analytics for an active process that actively seeking the identification of critical conditions through data analysis. Level 3 focuses on the proactive process that identifies potential future problems and turning data into actionable information.

\section{TRANSFORMING RAILWAY SUPPLIER SELECTION}

Information Technology (IT) provides higher profitability and industry change, with an accentuation on examinations directed at the industry level. The focal contention is the vast part of the estimation of IT on the capacity to empower integral hierarchical processes by enabling the organization to increase or improve quality and decision-making process as presented in Figure 9. 


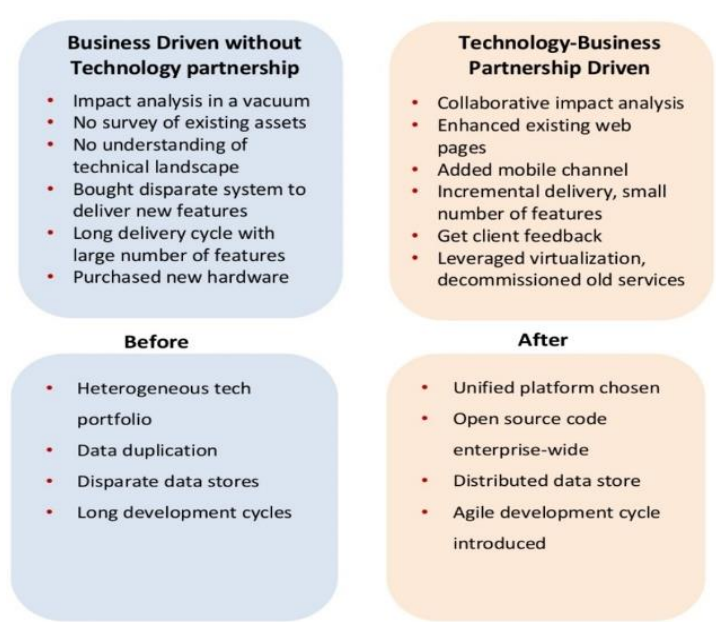

Figure 9. Transforming Business Driven to Technology-Driven Organizations.

Based on Figure 9, the transforming business into technology-driven organizations in railway supplier selection activities, and processes to occur electronically focusing on: (1) Communication is an essential delicate ability for individuals working in the organization and communicate effectively from passage level representatives to the $\mathrm{CEO}$, (2) Decision Making ranging from operation to how to determine a debate among workers and organization goals by enabling primary scholars who can gauge the advantages and disadvantages of an occasion and afterward settle on a choice, (3) Conflict Management skills in mediation and resolve the issues respectfully and appropriately and (4) Organization Ethical on handling sensitive information about the organization and sharing this information with the appropriate manner by keeping this information organized and accessible. The concept of railway supplier selection and technology focuses on the datasets that have been digitalized for decision-making techniques through new technology as shown in Figure 10.

\section{Business Driven Organizations:}

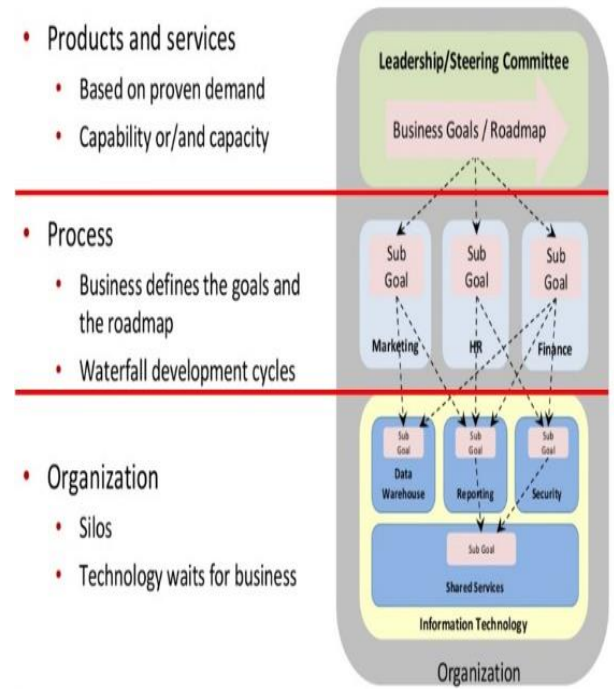

\section{Technology Driven:}

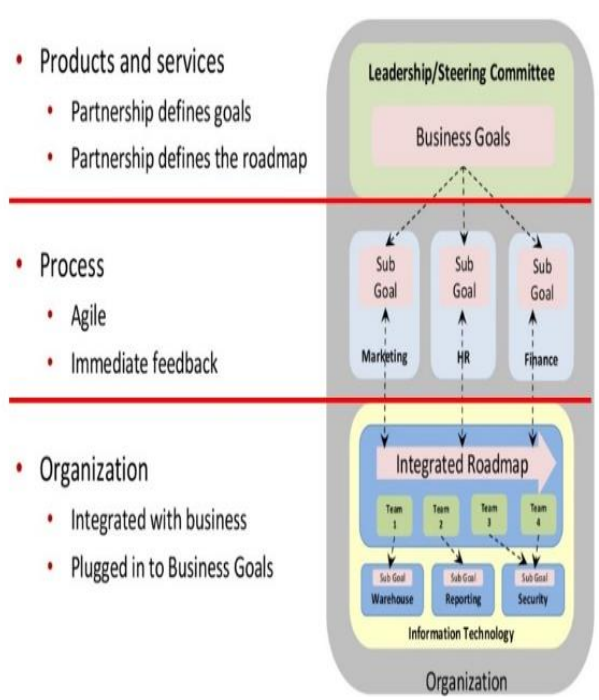

Figure 10. Technology Driven for Railway Supplier Selection.

Based on Figure 10, the technology-driven for railway supplier selection describes the unique capacity of analysis and planning for decision-makers in selecting the right supplier for specific railway projects. Moreover, we focus on the technology-driven as (1) Systems where IS emphasize a strategy organization system consists of the objectives, preconditions, rules, chosen principles and plans of IT applications for organization process and structure, (2) Perspectives focus information system as IT specialist's user on information, abilities, desire, and mentalities of the organization, (3) Development in IS for information and specialized foundation (data framework): the regular information and databases and (4) Quality in IS emphasize in management of IS function for information facilities by adjusting the previously mentioned subsystems. 


\section{CONCLUSION}

The research contributes to IS dimension and cybernetics perspective on information-seeking through data analytics phenomena using the cybernetics approach as an application tool for strategic railway supplier selection. The proposed framework for strategic performance has been derived from the strategic works of literature of IS and incorporated with the OC. Thus, the adapted strategic planning model for Railway Supplier Selection of Information System and Organizational Cybernetics as research work for implementing and evaluating the strategic performance management system in a holistic approach.

Besides, this proposed framework provides a diagnostics tool for simulation and optimization of data analytics and OC- multiple intelligences. This framework ensures that an organization's strategic plans and activities will be effectively and efficiently implemented using OC and IS technology by checking and controlling components and cycles in the unique circumstance and complexities of data analytics and OC maps of performance diagnostics dashboard. Further work had forwarded designing and developing real and specific railway supplier selection diagnostics dashboards.

\section{ACKNOWLEDGEMENTS}

The authors wanted to thank the editor and reviewers for their positive suggestions and comments for correcting the nature of this article.

\section{REFERENCES}

[1] M. Jayakrishnan, A. K. Mohamad, and M. M. Yusof, "Digitalization Railway Supply Chain 4.0: Enterprise Architecture Perspective," Int. J. Adv. Trends Comput. Sci. Eng., vol. 9, no. 5, pp. 9056-9063, 2020.

[2] V.-H. Lee and K.-B. Ooi, "Applying the Malcolm Baldrige National Quality Award criteria: an approach to strengthen organisational memory and process innovation," Total Qual. Manag. Bus. Excell., vol. 26, no. 11-12, pp. 1373-1386, Dec. 2015.

[3] R. Glanville, "Living in cybernetics," Kybernetes, vol. 44, no. 8/9, pp. 1174-1179, Sep. 2015.

[4] V. Venkatesh, J. Y. L. Thong, F. K. Y. Chan, P. J. H. Hu, and S. A. Brown, "Extending the two-stage information systems continuance model: Incorporating UTAUT predictors and the role of context," Inf. Syst. J., vol. 21, no. 6, pp. 527-555, 2011.

[5] C. Westermann, "The art of conversation: design cybernetics and its ethics," Kybernetes, vol. ahead-of-p, no. ahead-of-print, Mar. 2020.

[6] M. Jayakrishnan, A. K. Mohamad, and M. M. Yusof, "Strategic Information System for Decision Making in Railway Supply Chain Management," Int. J. Adv. Trends Comput. Sci. Eng., vol. 9, no. 3, pp. 3988-3994, 2020.

[7] A. Vahidi, A. Aliahmadi, and E. Teimoury, "Researches status and trends of management cybernetics and viable system model," Kybernetes, vol. 48, no. 5, pp. 1011-1044, May 2019.

[8] E. M. Rogers, Diffusion of innovations. 1995.

[9] T. H. Davenport, "Competing on analytics," Harv. Bus. Rev., vol. 84, no. 5, p. 150, 2006.

[10] A. V. Jdanko, "Evolutionary Cybernetic Systems Theory Considered as a Chapter of General Systems Theory A Viewpoint," Kybernetes, vol. 17, no. 5, pp. 44-51, May 1988.

[11] A. Kearny, C., Gerber, A. and van der Merwe, "Data-driven enterprise architecture and the TOGAF ADM phases.," in In 2016 IEEE International Conference on Systems, Man, and Cybernetics (SMC), 2016, pp. 004603004608 .

[12] M. Jayakrishnan, A. K. Mohamad, and M. M. Yusof, "Business Architecture Model in Strategic Information System Management for Effective Railway Supply Chain Perspective,” Int. J. Eng. Res. Technol., vol. 13, no. 11, pp. 3927-3933, 2020.

[13] A. K. Mohamad, M. Jayakrishnan, and N. H. Nawi, "Classification of Twitter Data by Sentiment Analysis in the Malay Language,” Int. J. Emerg. Trends Eng. Res., vol. 8, no. 6, pp. 2730-2738, 2020.

[14] M. Jayakrishnan, A. K. Mohamad, and M. M. Yusof, "Knowledge Management System for Railway Supply Chain Perspective," J. Online Inform., vol. 5, no. 2, 2020.

[15] J. C. Henderson and H. Venkatraman, "Strategic alignment: Leveraging information technology for transforming organizations," IBM Syst. J., vol. 32, no. 1, pp. 472-484, 1993.

[16] A. C. Edmondson, "Strategies for learning from failure," Harvard Bus. Rev., vol. 89, no. 4, pp. 48-55, 2011.

[17] J. F. George, Information Technology and Innovation Trends in Organizations. ItAIS: The Italian Association for Information Systems: Foreword, 2011.

[18] M. Jayakrishnan, "Analysis Of Socio-Technical Factors In Business Intelligence Framework Case Study Of Higher Learning Institution,” Universiti Teknikal Malaysia Melaka, 2018.

[19] F. Romero, D. and Vernadat, "Enterprise information systems state of the art: Past, present and future trends.," Comput. Ind., vol. 7, no. 9, pp. 3-13, 2016.

[20] W. J. Orlikowski and D. Robey, "Information Technology and the Structuring of Organizations," Inf. Syst. Res., vol. 2, no. 2, pp. 143-169, Jun. 1991. 